aanwezigheid der effecten en schuldbekentenissen van ondershandse leningen met publiekrechtelijke lichamen en de eigendomsbewijzen der vaste goederen, ingevolge Art. 17 der Statuten, door de Raad van 'loezicht geschiedt, terwijl de waardepapieren in Indië aanwezig door Heren Commissarissen van dat kantoor werden gecontroleerd.

Ik kan niet inzien, dat de accountant zelfs bij dergelijke bestaande statutaire voorschriften niet de leiding zal kunnen nemen bij de opneming van de effectenvoorraad.

Voor wiskundige reserve wordt verwezen naar de opgaaf van den actuaris.

Uiteraard wordt na dit onderzoek, dat in feite voor het maatschappelijk financieel verkeer van weinig warde is, de jaarrekening door den accountant niet getekend.

Diverse ondernemingen.

Nog een twintigtal jaarverslagen van diverse maatschappijen werd door mij nagegaan. Meerdere behoren tot de officieel genoteerde fondsen, andere niet.

Veel interessants voor ons onderzoek is er niet bij.

Een enkele uitzondering vormt een brief, die is afgedrukt in het jaarverslag van de Semarang Joana Stoomtram Mij., gericht aan Heren Bewindvoerders der N.V.

Deze brief bevat enkele merkwaardige passages, waarvan hier enkele mogen volgen:

Accountants hebben een ,beperkte" controle uitgeoefend op de ,concept"-jaarrekening.

"Volgens" Lw verzoek vond dit "onderzoek" op dezelfde wijze plaats als in de voorafgaande jaren, nl.:

De uit Indië ontvangen gegevens hebben wij ,zonder contrōle onzerzijds aanvaard", terwijl wij ons ten aanzien van de te 's-Gravenhage gevoerde boekhouding ,ten dele" tot "steekproeven" beperkten. De boekingen in de hulpboeken zijn ",steekproefsgewijs" geverifieerd met de originele bescheiden, waarbij wij geen verschillen constateren.

Ten aanzien van de toevoegingen aan de Afschrijvingsrekening Spoorwegbedrijf, overtuigden wij ons, dat het bestaande, $U$ bekende afschrijvingsstelsel consequent is voortgezet, zonder dat het cijfermateriaal over voorgaande jaren, waarop de berekening gebaseerd is, door ons werd gecontroleerd. De betreffende berekeningen hebben wij ..steekproefsgewijs" nagegaan".

Of en in hoeverre de afschrijvingsrekeningen........ een clement van reëele reserve inhouden ,,valt buiten onze beoordeling".

"In hoeverre de bijdragen aan Pensioenfonds en Ondersteuningsfonds juridische verplichtingen der maatschappij vormen, ,valt buiten onze beoordeling".

,De administraties van het pensioenfonds en het Ondersteuningsfonds werden niet door ons gecontroleerd

"De waardering van het Kantoorgebouw te 's-Gravenhage valt buiten onze beoordeling".

,Resumerend kunnen wij verklaren, dat het onderzoek ons de .,indruk" gaf, dat de administratie in alle opzichten uitstekend verzorgd is en dat wij geen enkele aanleiding vonden om de juistheid van bijgaande jaarrekening in twijfel te trekken."

Een dergelijk rapport is m.i. niet voor publicatie geschikt. Een onderzoek als omschreven wekt te veel vertrouwen, ondanks de vele voorbehouden, die het illusoir maken. Aan de laatste alinea zou men kunnen toevoegen, dat het onderzoek onvoldoende waarborg geeft voor de "indruk", dat de jaarrekening wel juist is.

Besluit.

Ik ben thans aan het einde gekomen van mijn uiteenzettingen. lk hoop dat zij iets mogen bijdragen tot meerdere soberheid cn uniformiteit van de accountantsverklaring in de gepubliceerde Nederlandse Jaarverslagen. Hieraan mag worden toegevoegd, dat reeds meerdere verklaringen reeds geheel of bijna geheel aan de cloor mij in de annvang van dit artikel gestelde eisen voldoen. Hoewel het onderzochte materiaal nog bescheiden van omvang is, in verhouding tot het totaal beschikbare, geloof ik toch, dat de getrokken conclusies verantwoord zijn, daar meer dan 150 Jaarverslagen zijn nagegaan, waarbij wel het merendeel van onze grote Nederlandse bedrijven.

H. H. M. FOPPE

Accountant N.I.v.A.

\section{NIEUWS IN ZAKE WETGEVING, RESOLUTIES EN BESLISSINGEN OP HET GEBIED DER BELASTINGEN}

\section{Red.: Mr Dr E. TEKENBROEK}

(Bijdragen en mededeelingen zende men aan den Secretaris der Redactie)

\section{Vinden bij een ontbinding van een firma belastbare leveringen voor de omzetbelasting plaats?}

lemand oefende het beroep van fabrikant uit in een firma; de firma werd ontbonden, bij de daarop volgende scheiding van de vennootschappelijke boedel werd hem een deel der voorraden toegescheiden. Hij verkocht die voorraden als handelaar, zonder (in feitelijke $z$ in) fabrikant meer te zijn, daar hij onmiddellijk na zijn uittreden uit de firma zich gevestigd had als handelaar. Van hem werd over die verkoopen omzetbelasting nagevorderd; als verweer droeg hij voor dat hij geen fabrikant was en die verkoopen ook geen liquidatie-handelingen waren, maar geschieden in zijn bedrijf van handelaar.

De Tariefcommissie handhaafde de navorderingsaanslag. In verband met het declaratoire karakter der scheiding (art. 1689 juncto art. 1129 B.W.) achtte de Tariefcommissie bij de scheiding geen levering aanwezig, zoodat op dat moment geen omzetbelasting geheven kon worden. Maar de verkoopen van de hem toebedeelde artikelen beschouwde de Tariefcommissie als liquidatie-handelingen, bij het verrichten warvan de qualiteit van fabrikant nog op de gewezen firmant ruste.

Uit een oogpunt van redelijke wetstoepassing kan men vrede met die uitspraak hebben, maar juridisch beschouwd lijkt ze ons niet bijster fraai. Hoe kan na een reeds voldongen scheiding, dus na beëindiging van de liquidatie, nog liquidatiehandelingen plaats vinden. Kennelijk wil de Tariefcommissie in deze aan het begrip liquidatie een feitelijke en geen juridische inhoud geven. De formeele juristerij omtrent het declaratoire karakter van de scheiding in de zelfde uitspraak doet dan echter vreemd aan.

\section{Verkapte winstuitdeeling}

De rechtspraak over verkapte winstuitdeelingen is wederom verrijkt met een uitvoerig gemotiveerde uitspraak van de Amsterdamsche Raad van Beroep, door de Hooge Raad met zijn arrest dd. 23 November 1938 (B 6781) bevestigd, dat alle aandacht verdient. De casus positie was nogal ingewikkeld en de uitspraak is te uitvoerig om in deze rubriek geheel behandeld te kunnen worden. De Raad van Beroep stelde o.m. Feitelijk vast dat om niet zakelijke redenen, maar om een groot aandeelhouder te gerieven, de N.V. een risico op zich heeft genomen, welk risico anderhalve maand na de transactie, in 
het zelfde boekjaar nog, een groot verlies opleverde. Van groot belang achten wij na te gaan wanneer in zoo'n geval van risico-overname de belastbare uitdeeling geacht kan worden te hebben plaats gehad en hoe groot die was.

In dit verband $z$ ijn de volgende overwegingen van de Raad van Beroep van belang:

.,7. dat wanneer een n.v. niet om zakelijke redenen, ,doch ten gerieve van de deelgerechtigden in haar winst ,een risico aanvaardt in de aanvaarding van zulk een "risico een uitdeeling moet worden gezien, die tot het ,,bedrag van het daaruit voor haar voortvloeiende ver,lies - voorzoover dit redelijkerwijze geacht kan wor"den definitief te zijn geleden en door de in haar aan,wezige winst wordt gedekt — als belastbare winstuit„,deeling moet worden beschouwd; 8 . dat het daarbij on,,verschillig is of al dan niet de winstgerechtigden het ,,verlies dat als gevolg van dat risico is geleden, reeds ,,aanstonds als waarschijnlijk konden voorzien en door ,die vennootschap tot de aanvaarding van dat risico te ,bewegen, het oogmerk hebben gehad on op deze wijze "over haar winst te beschikken;"

,11. dat aangezien nog in hetzelfde boekjaar, waarin ,genoemde transactie is tot stand gekomen de geheele ,,voor den aankoop der aandeelen en winstbewijzen ge.geven koopprijs tengevolge van het waardeloos worden "dier aandeelen definitief is verloren en het desbetref"fende bedrag van $f$ 122.000. - uit de in belangheb,bende aanwezige winst kan worden gedekt, de aanslag ,terecht naar een belastbare uitdeeling van dat bedrag ,is geregeld;"

De Hooge Raad overwoog in zijn arrest te dien aanzien:

,,dat, nu dit geschiedde niet om redenen van eigen ,zakelijk belang van belanghebbende, doch om haar ,eenige aandeelhoudster te gerieven en binnen enkele .maanden in hetzelfde boekjaar bleek, dat het aanvaar„, den van dit risico belanghebbende kwam te staan op ,een verlies van $f 122.000$, de raad van beroep zonder ,schending of verkeerde toepassing van de in de mid. ,delen aangehaalde wetsartikelen kon beslissen, dat .,door de transactie in het betrokken boekjaar een uit,deeling van $f 122.000$ ten behoeve van deelgerechtig, den in de winst had plaats gevonden, welke, als gedekt ,uit winst van belanghebbende, met dividend- en tan,,tièmebelasting moet worden belast;"

Wij zijn geneigd uit een en ander te concludeeren dat als moment van uitdeeling gekozen is het moment, waarop de transactie plaats vond. De grootte der uitdeeling werd bepaald door schatting van het risico, naar objectieve gegevens; het subjectieve inzicht van de winstgerechtigde stelt de Raad v. Beroep ter zijde. Door het feit, dat binnen $1 \frac{1}{2}$ maand het verlies op die transactie geleden f 122.000. - bedroeg. mocht de Raad van Beroep feitelijk beslissen dat dit risico op f 122.000. - te stellen was.

Met groote stelligheid durven wij, althans wat het standpunt van de R. v. B. betreft deze conclusie niet te trekken. De hierboven vermelde overwegingen 7 en 8 van de R. v. B. laten n.l. ruimte voor de opvatting, dat de grootte der uitdeeling steeds te stellen is op het verlies dat uiteindelijk uit de transactie resulteert. De hierboven vermelde overweging van de H.R. laat ik te dien aanzien minder ruimte. Het zou interessant geweest zijn te ervaren op welk bedrag de R. v. B. de belastbare uitdeeling gesteld zou hebben, als het defini tieve verlies op de transactie niet $11 \%$ maand na dien en in het zelfde boekjaar maar bijv. cen jaar later geleden zou zijn.

\section{Afschrijving op en waardeering van bedrijfsmiddelen}

Met zijin arrest d.d. 19 October 1938 (B 6761) besliste de Hooge Raad dat het voor de berekening van het zuiver inkomen ongeoorloofd is een systeem te volgen, dat medebrengt dat wegens slijtage jaarlijks op onroerend goed wordt afgeschreven en bovendien indien de verkoopwaarde alsdan nog geringer is dan de boekwaarde, het onroerende goed op die verkoopwaarde te stellen. Bij een stelsel van jaarlijksche waardeering naar verkoopwaarde, dat o.m. met zich brengt, dat een waarde-stijging op de balans tot uiting komt, past een afschrijving wegens slijtage volgens ons hoogste rechtscollege niet.

Men doet goed bij de beoordeeling van de draagwijdte de in de Maart aflevering van dit blad op pg. 41 vermelde uitspraak van de Raad van Beroep te Amsterdam het hierboven vermelde arrest in aanmerking te nemen.

\section{Speculatie-winst of opbrengst van op zich zelf staande werkzaamheden}

,Van winst enkel ontstaan door speculatie kan slechts worden gesproken, indien de uitslag van de transactie, waaruit zij voortvloeit, uit den aard der zaak uitsluitend afhankelijk is van onvoorzienbare factoren, die door de arbeid van den betrokkene niet kunnen worden beinvloed."

Aldus trekt de Amsterdamsche Raad v. Beroep in deze de scheidingslijn, waarmede de Hooge Raad accoord ging. (zie arrest d.d. 28 Sept. '38 B 6747).

\section{Wat is navorderen?}

Aan een belastingplichtige was voor het belastingjaar $1934 / 35$ een navorderingsaanslag in de I.B. opgelegd, die ge dateerd was op $12 \mathrm{Mei}$ '37. Aangezien de belastingplichtige zich op het standpunt stelde, dat onder navorderen is te verstaan het brengen van de naam van den belastingplichtige en het door hem te betalen bedrag ten kohiere, voerde hij als verweer dat de navordering te laat plaats vond.

In een uitvoerig gemotiveerd arrest betoogt de H.R., dat onder navorderen is te verstaan het vaststellen van een aanslag tot navordering.

Het vaststellen van een aanslag geschiedt doordat de met de vaststelling belaste autoriteit de aanslag te boek stelt op het bij de belasting-administratie in gebruik zijnde register van aanslagen en die te-boek-stelling onderteekent. Aangezien uit een verklaring van den Inspecteur bleek dat die te-boekstelling en onderteekening vóór $1 \mathrm{Mei}$ '37 was geschied, werd aangenomen dat de opgelegde aanslag als zijnde binnen de daarvoor gestelde termijn was vastgesteld.

In het ten kohiere brengen van een aanslag ziet de H.R. het verkrijgen van de titel van invordering en dus niet de daad der navordering zelf. (Arrest H.R. 23 Nov. '38 B 6782).

\section{Ambtelijk verzuim}

lemand had zijn niet ter beurze genoteerde effecten bij zijn aangifte gewaardeerd op $f$ 2000.- en als inkomen daaruit ruim $f$ 4000. - aangegeven. De aanslag werd conform aangifte opgelegd. Uit een later ontvangen accountantsrapport bleek den Inspecteur dat de waarde der aandeelen niet op $f$ 2000. - maar op ruim $f$ 16000. - gesteld moest worden. De Inspecteur legde een navorderingsaanslag op. De belastingplichtige stelde dat hier een ambtelijk verzuim was, 
daar uit de verhouding tusschen aangegeven waarde en de opbrengst den Inspecteur bij het vaststellen van de primitieve aanslag had moeten blijken, dat de aangegeven waarde te laag was.

De navorderingsaanslag werd door de Utrechtsche Raad van Beroep gehandhaafd, waartoe als argumenten dienden:

1. Vergelijking met vorige aangifte gaf den Inspecteur geen enkel vermoeden van onwaarschijnlijkheid.

2. De Inspecteur had vermoed dat de opgegeven opbrengst ad ruim $f$ 4000. - in een verkeerde rubriek waren ge plaatst; de aangiften van de belastingplichtigen waren steeds nogal slordig.

De H.R. bekrachtigde de uitspraak (arrest dd. 12 Oct. '38 B 6753). Implicite blijkt uit de uitspraak, dat in een geval als het onderhavige wel eens een ambtelijk verzuim kan schuilen.

\section{Kantoor aan huis en P.B.}

Het komt veel voor dat iemand zijn kantoor thuis heeft. Voor de personeele belasting is het natuurlijk voordeelig als in zoo n geval aangenomen wordt, dat twee perceelen aanwezig zijn. Met een beroep op art. $2 \S 2$ P.B. dat van afzonderlijk in gebruik zijnde gedeelten van gebouwen rept, trachtte iemand die een deel van zijn woonhuis gebruikte als kantoor van een vereeniging van huiseigenaren, waarvan hij administrateur is, het aanwezig zijn van twee perceelen aangenomen te krijgen.

De R. v. B. te Zwolle, zoomede de H.R. wilden daar echter niet aan. In het beroepschrift in cassatie was o.m. gesteld, dat de twee gedeelten van het huis voor verschillende doeleinden worden gebruikt. De H.R. meent dat daaruit nog niet volgt: afzonderlijk gebruik van de betrokken perceelsgedeelten.

\section{Tijdstip van uitdeeling bij een verkapte winstuitdeeling}

In de boeken van de N.V. A stond een vordering op de firma $B$, waarvan een groot aandeelhouder van $A$ eenig firmant was. In de loop van 1934 wordt deze vordering via de Verlies- E winstrekening afgeboekt. Noch de Inspecteur noch de Raad van Beroep, noch de H.R. accepteeren de voorgegeven causa dier afboeking en achten hier een belastbare uitdeeling aanwezig. Voor de I.B. rees nu de kwestie of die uitdeeling in 1934, dan wel in 1935 (het jaar warin de jaarstukken der N.V. A over 1934 werd vastgesteld) als gedaan dient te worden beschouwd, welke kwestie van belang is voor de aangiften voor de Inkomstenbelasting van 1935/36 en $1936 / 37$.

Deze vraag kan bij dergelijke verkapte uitdeelingen meer rijzen. Tegenover het betoog van den aandeelhouder dat op het moment van de boeking het bedrag als ,vastgesteld" beschouwd moet worden, stelde de inspecteur dat eerst nadat de Alg. Verg. de balans had goedgekeurd ondubbelzinnig en definitief door de N.V. tot uitdrukking is gebracht dat ze den aandeelhouder heeft willen bevoordeelen. De afboeking had wel eerder plaats gehad, maar uit de omschrijving bleek in deze niet ondubbelzinig van een definitieve uitkeering.

Deze overweging was als zijnde van feitelijke aard in cassatie onaantastbaar.

\section{E. TEKENBROEK}

\section{UIT HET BUITENLAND}

Red.: F. HAARBOSCH, CH. HAGEMAN, Drs D. NIJE en Drs W. P. DEN TURK

(Bijdragen en mededeelingen zende men aan den Secretaris der Redactie)

\section{Losbladige registers}

Der Buch- und Steuerberater van 15-3-'39 geeft enkele opmerkingen over de contrôle op het losbladige register.

1. Nummerverwijzing tusschen boekingsstuk, rekening en doorslagsgewijze verkregen recapitulatie der boekingen (inkoopboek, verkoopboek, proofsheet) is noodig.

2. Registratie van voorraden en van in gebruik gegeven losse bladen is vereischt. Zonder dat heeft nummering maar weinig beteekenis.

3. Jaarlijks of halfjaarlijks nieuwe bladen in gebruik nemen en de bladen der afgeloopen periode in hun geheel afleggen.

4. Het voorzien der losbladige registers van een slot heeft de meeste beteekenis wanneer bij iedere aanvulling wordt gecontroleerd of transport van saldo dan wel van tellingen juist geschiedt.

T.a.v. punt 2 maakt de auteur van het artikel, Lohmann. een interessante opmerking. Zulk een administratie kan worden gehouden door of onder toezicht van een hooger functionaris. Dat is kostbaar. Ze kan ook worden gehouden doo: lager personeel. Dan daalt haar contrôlewaarde.

Bij kaartsystemen is daarom gebruik te maken van de z.g. Leitkarte. Die geeft contrôle en tegelijkertijd informatie voor den gebruiker. Maar ze kan ook worden vervalscht. Supplement-geleidekaarten kunnen aan de aandacht zoowel van den internen controleur als van den accountant worden onttrokken, tenzij op de eerste in gebruik genomen geleidekaart duidelijk in inkt staat aangegeven dat er meerdere zijn.

Merkwaardigerwijze wordt niet genoemd als basis van alle contrôle: de totaalcontrôle middels het grootboek. Zoo ooit, dan geldt zeker van alle administraties die in losbladige boeken worden gehouden, dat ze sub-grootboekkarakter moeten bezitten.

Rotterdam, Maart 1939.

d. T.

\section{BOEKBESPREKING}

Vraagstukken over Accountancy. verzameld door M. G. Mey-Koning. Deel I Inrichtingsleer. J. Muusses, Purmerend.

Mevrouw Mey-Koning, echtgenoote van collega Drs. $A$. $M e y$, heeft een belangrijk werk verricht door de uitgave van een 200 tal examen-vraagstukken der laatste 12 jaren." 1)

T'eneinde tot een rubriceering te komen die zich aansluit bij de grondslagen der inrichtingsleer, heeft de auteur naar twee zijden tegelijk gewerkt. Hoofdstukindeeling naar bedrijven, daarnaast rangschikking naar onderwerpen. 2 ) Door een decimaal aanduidingsstelsel wordt men wegwijs in de geboden materie.

Dit prijzenswaardig werk geeft aanleiding tot het behandelen van eenige algemeene kwesties.

1) $Z_{\text {ij }}$ zijn afkomstig van het N.I.v.A., de universiteiten van Rotterdam. Amsterdam en Tilburg en van het Rijksexamen.

2) Het werk van R. A. Dijker no. V van de Delwel-serje (1923) bevat reeds een nog steeds bruikbare handleiding. Merkwaardig is dat de bedrijfseconomische onderwerp-inudeeling van Dijker, die van Mevr. Mey ten deele evenaart. 